
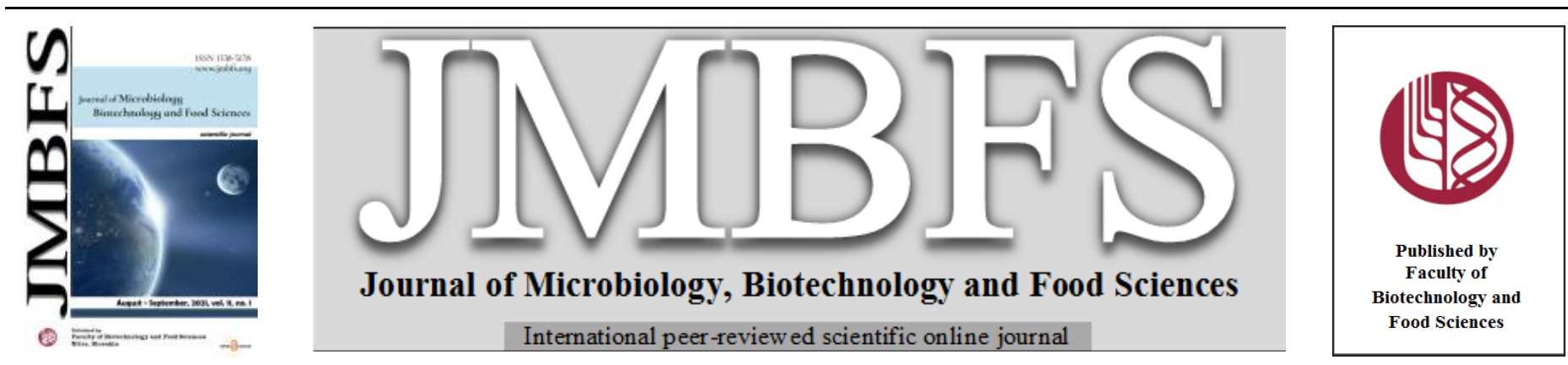

\title{
CONSUMER PREFERENCE STUDY ON COMBINED ULTRASOUND AND SODIUM HYPOCHLORITE TREATED FRESHCUT KIWIFRUITS COATED WITH CHITOSAN USING THE FUZZY LOGIC APPROACH
}

\author{
Kambhampati Vivek * ${ }^{1,2}$, Singam Suranjoy Singh ${ }^{3}$, Raju Sasikumar ${ }^{4}$, Rokayya Sami $^{5}$ \\ Address(es): Dr. Kambhampati Vivek \\ ${ }^{1}$ Food Technology and Management, Indian Institute of Plantation Management, Bengaluru, Karnataka - 560056, India. \\ ${ }^{2}$ Department of Food Engineering and Technology, Tezpur University, Tezpur, Assam - 784028, India. \\ ${ }^{3}$ School of Engineering, University of Guelph, Guelph - N1G 2W1, ON, Canada. \\ ${ }^{4}$ Department of Agribusiness Management and Food Technology, North Eastern Hill University (NEHU), Tura Campus, Meghalaya - 794002, India. \\ ${ }^{5}$ Department of Food Science and Nutrition, College of Sciences, Taif University, P.O. 11099, Taif 21944, Saudi Arabia.
}

*Corresponding author: vivek.tezu@gmail.com; vivek.kambhampati@iipmb.edu.in

https://doi.org/10.15414/jmbfs.4054

\section{ARTICLE INFO}

Received 8. 12. 2020

Revised 6. 3. 2021

Accepted 10. 3. 2021

Published 1. 8. 2021

Regular article

open $C_{\text {ACCESS }}$

\begin{abstract}
Fresh cut kiwi fruits are gaining popularity among consumers due to increased nutrition, health, and convenience. In this study ultrasound treated fresh cut kiwifruit slices were coated with different concentrations $(0.6,0.8$, and $1 \%)$ of chitosan. Sensory evaluation was conducted in linguistic terms for the kiwifruit slices with a panel of 15 well-trained judges to understand the consumer preference. The linguistic approach was analysed and decoded using the fuzzy logic modeling approach to find the best sample and quality attribute responsible for consumer preference. The slices with the highest defuzzified scores were obtained for the $1 \%$ chitosan-coated sample. Ranking of kiwifruit slices was based on defuzzified scores was $\mathrm{S} 1>\mathrm{S} 2>\mathrm{S} 3>\mathrm{S} 4$, while ranking of the quality attributes was smell>taste>color>texture. Therefore, the fuzzy logic modeling could be a practical approach for finding the consumer preference of fresh cut kiwifruits, thus increasing product marketability.
\end{abstract}

Keywords: Fresh cut kiwifruits, Ultrasound, sodium hypochlorite, chitosan-coating, fuzzy logic sensory approach

\section{INTRODUCTION}

Fruits are a vital source of essential nutrients and take a pivotal role in maintaining our body fit and healthy. Hence fruits should be considered as a routine part of our diet. The growing concern about nutrition, quality, sensory, and convenience of foods resulted in increasing consumer demand for fresh cut fruits. However, microbial hazards pose a serious threat to the fresh cut commodity in terms of product wastage and foodborne illness caused by pathogens. Among fruits, kiwi offers plenty of health benefits and is packed with a rich taste and aroma. They are rich sources of carotenoids, phenolic compounds, and flavonoids, which reduce the risk of cancer, cardiovascular, and degenerative diseases (Amodio et al., 2007). Ripened kiwifruits are fussy to peel due to thin skin and delicate handling; thus, the demand for fresh cut kiwifruit increases. Moreover, ripened fresh cut kiwifruits offer less shelf life and often spoil in 1 to 2 days, even at the refrigerated storage temperatures. Therefore, there is a need for technology to enhance the shelf life of fresh cut kiwifruits.

Ultrasound is considered an innovative and promising technology to preserve fresh cut fruits' quality (Knorr et al., 2004). The technology has exclusive leverage over other non-thermal technologies for reducing spoilage while maintaining the sensory attribute of fruits (Knorr et al., 2004; Stojanove and Silava, 2007). However, ultrasound pre-treatment alone cannot increase the shelf life of the fresh cut commodity. An ultrasound treatment followed by proper packaging or coating is essential to improve the shelf life and maintain their freshness and taste (Helander et al., 2001; Vivek et al., 2016). Chitosan is a high molecular weight linear chain polysaccharide consists of D-glucosamine (deacetylated unit) and N-acetyl-D-glucosamine (acetylated unit) linked by randomly distributed $\beta-(1-4)$ linkage. It is used as an edible coating material on fruits to improve the storage shelf life by controlling microbial and non-microbial decay. Fruits like litchi (Zhang and Quantick, 1997), pears (Lin et al., 2008), grapes (Meng et al., 2008), chestnut (Pen and Jiang, 2003), and strawberry (Hermandz-Munoz et al., 2008) were coated with chitosan to extend the shelf life and preserve the natural qualities of the fruits. The sensory evaluation of chitosan-coated fresh cut fruits is needed to know the consumer satisfaction and support research and development (Fattahi and Babri, 2010).
Sensory evaluation is an analytical tool that clarifies how the products are perceived through the human senses (hearing, touch, sight, taste, and smell). It plays a major role in food quality control and new product developments. It can be categorized into the affective and descriptive analysis. Conventionally, consumer scores for all the sensory attributes like flavor, color, aroma, etc. involved in the sensory study were analyzed statistically. But the sensory scores obtained by human senses are imprecise and uncertain (Martinez, 2007). This makes the sensory analysis critical to understand and involve uncertain knowledge. The strength and weakness of a food product with defined quality attributes determines the acceptance or rejection of the product in the market place. Fuzzy logic is a form of many-valued logic that solves problems in the imprecise spectrum of data collected from the sensory study. The uncertain phenomenon in sensory evaluation can be solved mathematically using fuzzy logic (Jaya and Das, 2003). The technique is a linguistic approach that uses the raw sensory data collected from the customers or evaluators in linguistic terms viz. satisfactory, not satisfactory, good, excellent, etc., and the degree of vagueness in their perception will be converted to a real number (Perrot, 2006). The linguistic variables are used to develop a relationship with quality attributes and results (acceptance or rejection). The fuzzy set theory is enforced to accord with linguistic data. It permits the gradual assessment of the membership of elements in a set that is interpreted with the aid of a membership function (MF) between 0 to 1 (Das, 2005; Lazim and Suriani, 2009). Various authors have reported on the fuzzy logic analysis of sensory data to find the best sample and important quality attribute responsible for acceptance (Jaya and Das, 2003; Das, 2005; Perrot, 2006; Martinez, 2007; Lazim and Suriani, 2009). Therefore, fuzzy logic could be an important decision-making tool for identifying the quality attributes responsible for the acceptance in the case of chitosan-coated fresh cut kiwifruit samples. However, no literature is available on the consumer preference study of ultrasound treated and chitosan-coated fresh cut kiwifruits. Hence, the present work's main objective is to determine the sensory characteristics of ultrasound treated fresh cut kiwifruits coated with chitosan at different concentrations and compared with an un-coated fresh cut kiwifruit. The overall acceptance and the dominating sensory attributes, viz smell, taste, color, texture was assessed and ranked using fuzzy analysis. 


\section{MATERIALS AND METHODS}

\section{Raw materials - fresh cut kiwifruit preparation}

Hayward kiwifruits were hand-harvested in the month of late November 2015 at a commercial farm in Dirang Valley (Arunachal Pradesh, India) and transported to the Food Engineering Laboratory, Tezpur University, Assam, India within 12 hours. The initial total soluble solid (TSS) of the fruits was $9 \pm 0.5 \%(\mathrm{w} / \mathrm{w})$ (Vivek et al., 2019). The fruits were thoroughly checked and selected for uniform dimension, absence of visual wounds, and defects free for the experiment. Raw kiwifruits were treated with ultrasound combined with $100 \mathrm{ppm}$ of sodium hypochlorite $(5 \% \mathrm{w} / \mathrm{v}$, available chlorine) for 8 minutes (Vivek et al., 2017) Then the samples were air-dried at $25{ }^{\circ} \mathrm{C}$ for 15 minutes. The fruits were hand peeled and transversely sliced with a stainless-steel knife. Chitosan (MW: 760 $\mathrm{kDa}$, degree of deacetylation $>75 \%$ ) was procured from Sigma-Aldrich. The coating was done at various concentrations of chitosan $(0 \%, 0.6 \%, 0.8 \%$, and $1 \%$; w/V) with $1 \%$ acetic acid solution as solvent. An acidic solution of $0.1 \mathrm{M} \mathrm{NaOH}$ was used to adjust the $\mathrm{pH}$ of the coating solution to 5.0, while an acid solution at the same $\mathrm{pH}$ without chitosan was considered as a control. Fresh cut kiwifruits were submerged into the chitosan solutions for $1 \mathrm{~min}$. The fruit slices were kept in the previously sterilized zip wrap pouches after being air-dried at $25^{\circ} \mathrm{C}$ for 15 min, and then the samples were stored at $5{ }^{\circ} \mathrm{C}$ for ten days. Different chitosan concentrations of $1,0.8$, and $0.2 \%$ for samples 1,2 , and 3 , respectively, were marked before storage. A sample without coating was considered as a control sample (sample 4).

\section{Obtaining sensory scores for the chitosan-coated fresh cut kiwifruits}

A well-trained panel consists of 15 judges were screened and involved in the sensory evaluation process of chitosan-coated fresh cut kiwifruits. All the panelists were asked for their interest and willingness to participate in the sensory study on a regular basis. Proper guidelines and training about the product were given to all the panelists before the sensory evaluation. Panelists were punctual and in good health condition throughout the study. Different quality attributes, terminologies, score sheets, and evaluation methods followed in the study were thoroughly explained to the panelists (Routray and Mishra, 2012). After each testing sample, the panelists were instructed to take the puffed rice and rinse their mouth with water to eliminate any residual effects. After evaluating each sample the panelists gave their preference by providing a tick $(\sqrt{ })$ mark in the given fuzzy linguistic score sheet. In the preference sheet, the samples and quality attributes were ranked as satisfactory, fair, medium, good, and excellent (Jaya and Das, 2003). In this study, MATLAB 14a (The Math Works Inc., Natick, MA) was used for all the calculation of sensory analysis data of chitosan-coated fresh cut kiwi fruits using a fuzzy logic approach.

\section{Fuzzy logic analysis}

The crucial steps necessary in the sensory evaluation of chitosan-coated fresh cut kiwifruits associated with the fuzzy modeling approach were:

1. Calculation of overall sensory scores (OSSs) for the chitosan-coated fresh cut kiwifruits in triplets form.

2. Membership function expression on a standard fuzzy scale (SFS).

3. Calculation of total membership function (MF) and the quality attributes for the chitosan-coated fresh cut kiwifruits based on the SFS.

4. Perception rating of quality attributes for the chitosan-coated fresh cut kiwifruits.

5. Computation of similarity values and ranking order for the chitosancoated fresh cut kiwifruits.

Computation of the total sensory scores for chitosan-coated fresh cut kiwifruits are as follows:

\section{Triangular fuzzy number and arithmetic operations}

The triangular fuzzy membership function (MF) is a five-point distribution arrangement of the sensory scale given in Jaya and Das, 2003. It represents the linguistic terms associated with the corresponding triplet values in the sensory scale such as 'poor/not satisfactory $(0,0,25)$ ', 'fair/somewhat important $(25,25$, $25)$ ', 'good/important $(50,25,25)$ ', 'very good/highly important $(75,25,25)$ ' and 'excellent/extremely important $(100,25,0)$. The triangular fuzzy number is a triplet ( $a, b, c)$ related to the sensory scale (Routray and Mishra, 2012). Here ' $a$ ' is the central value of a discrete set of a fuzzy number. It represents the $y$ coordinate of a point on the coordinate plane, in which the MF value is ' 1 '; ' $b$ ' and ' $c$ ' denote left, and right spreads in the sensory scale, at which the value of MF is ' 0 ' (Lazim and Suriani, 2009).
Calculation of triplets for sensory scores of chitosan-coated fresh cut kiwifruits and overall quality

The details of the sum of sensory scores, number of judges, and triplets accompanied with the sensory scale were used to calculate the triplets of specific quality attributes, i.e., color, aroma, mouthfeel, taste, and after taste in each sample. For example, in sample 1 (1\% chitosan-coated fresh cut kiwi fruits), color attribute out of ' 15 ' panelists, ' 9 ' panelists comply with an excellent score, ' 4 ' panelists comply with a good score, ' 1 ' panelists comply with fair, ' 1 ' panelists comply with medium, and ' 0 ' panelist comply with a not satisfactory score. Similarly, the different quality attributes for different samples were presented in Table 1. The triplets for sensory scores of a sample for any quality attribute could be calculated using Equation 1.

Srx $=$

$\frac{n_{1}(0,0,25)+n_{2}(25,25,25)+n_{3}(50,25,25)+n_{4}(75,25,25)+n_{5}(100,25,0)}{n_{1}+n_{2}+n_{3}+n_{4}+n_{5}}$

Here, ' $r$ ' represents the sample number, ' $x$ ' represents the color quality attribute, $\mathrm{n}_{1}$ to $\mathrm{n}_{5}$ represents the scores of judges in the corresponding linguistic terms (i.e. $\mathrm{n}_{1}$ judge corresponds to 'not satisfactory', $\mathrm{n}_{2}$ judge corresponds to 'fair', $\mathrm{n}_{3}$ judge corresponds to 'medium', $\mathrm{n}_{4}$ judge corresponds to 'good', and $\mathrm{n}_{5}$ judge corresponds to 'excellent') associated with the corresponding triplets in the sensory scale. Similarly, triplets for sensory scores of all the four samples in different quality attributes like the color $\left(\mathrm{S}_{2} \mathrm{C}, \mathrm{S}_{3} \mathrm{C}, \mathrm{S}_{4} \mathrm{C}\right)$, smell $\left(\mathrm{S}_{1} \mathrm{~S}, \mathrm{~S}_{2} \mathrm{~S}, \mathrm{~S}_{3} \mathrm{~S}\right.$, $\left.\mathrm{S}_{4} \mathrm{~S}\right)$, taste $\left(\mathrm{S}_{1} \mathrm{~T}, \mathrm{~S}_{2} \mathrm{~T}, \mathrm{~S}_{3} \mathrm{t}, \mathrm{S}_{4} \mathrm{~T}\right)$, and texture $\left(\mathrm{S}_{1} \mathrm{~T}_{\mathrm{x}}, \mathrm{S}_{2} \mathrm{~T}_{\mathrm{x}}, \mathrm{S}_{3} \mathrm{~T}_{\mathrm{x}}, \mathrm{S}_{4} \mathrm{~T}_{\mathrm{x}}\right)$ were calculated using the Equation 1 (Table 5). The triplets for quality attributes in general $\left(\mathrm{Q}_{\mathrm{C}}, \mathrm{Q}_{\mathrm{S}}, \mathrm{Q}_{\mathrm{T}}\right.$, and $\left.\mathrm{Q}_{\mathrm{Tx}}\right)$ were also calculated according to Equation 1 and presented in Table 6 . The corresponding weightage of each quality attribute was calculated using triplets for sensory scores of quality attributes and the sum of the first value in triplets (a) of all quality attributes, i.e., $Q_{\text {sum, }}$ and presented in Table 6 (Jha et al., 2016). The OSSs of the samples are calculated using the triplets for the sensory score of the sample and corresponding weights of each quality attributes, as mentioned in Equation (2).

$\mathrm{SO}_{\mathrm{i}}=\mathrm{S}_{\mathrm{i}} \mathrm{C} * \mathrm{QC}_{\mathrm{rel}}+\mathrm{S}_{\mathrm{i}} \mathrm{S} * \mathrm{QS}_{\mathrm{rel}}+\mathrm{S}_{\mathrm{i}} \mathrm{T} * \mathrm{QT}_{\mathrm{rel}}+\mathrm{S}_{\mathrm{i}} \mathrm{Tx} * \mathrm{QTX}_{\mathrm{rel}}$

Where $\mathrm{SO}_{\mathrm{i}}$ is the OSS of chitosan-coated fresh cut kiwi fruits, the subscript ' $\mathrm{i}$ ' indicates the sample number, $\mathrm{S}_{\mathrm{i}} \mathrm{C}, \mathrm{S}_{\mathrm{i}} \mathrm{S}, \mathrm{S}_{\mathrm{i}} \mathrm{T}$, and $\mathrm{S}_{\mathrm{i}} \mathrm{Tx}$ represent the triplets for the sensory scores of color, smell, taste, and texture attributes, respectively. Also, $\mathrm{QC}_{\text {rel }}, \mathrm{QS}_{\text {rel }}, \mathrm{QT}_{\text {rel }}$, and $\mathrm{QTx}_{\text {rel }}$ are the triplets related to the corresponding weightage of quality attributes of chitosan-coated fresh cut kiwi fruits in general. Similarly, the OSSs of all four samples were determined using Equation (2). The triplet's multiplication for two triplets $(a, b, c)$ and $(d, e, f)$ was performed using Equation 3.

$(a, b, c) *(d, e, f)=\left(a * d a * e+d^{*} b a * f+d * c\right)$

(3)

\section{Calculation of membership function (MF) on the standard fuzzy scale (SFS)}

A six-point scale (F1, F2, F3, F4, F5, and F6) with a set of 10 numbers each in a triangular distribution pattern as shown below was used to calculate the MF. In this distribution pattern, the values of fuzzy MF lie between 0 (minimum) to 1 (maximum) (Jha et al., 2015).

Calculation of overall membership function (OMF) of sensory scores on a standard fuzzy scale (SFS)

The SFS was associated with the overall quality of the chitosan-coated fresh cut kiwi fruits and expressed by a triplet (Lazim and Suriani, 2009). The MF value given as 'one' when the abscissa value is ' $a$ ', while the value is 'zero' when the abscissa is greater than ' $\mathrm{a}+\mathrm{c}$ ' or less than ' $\mathrm{a}-\mathrm{b}$ '. The MF value ' $\mathrm{Bi}$ ' for a given value of ' $i$ ' on the abscissa can be calculated using Equation (4). For a given value of ' $\mathrm{i}$ ' on the abscissa, the value of MF ' $\mathrm{Bi}$ ' can be calculated using Equation (4).

$$
\begin{aligned}
& \mathrm{Bi}=\frac{\mathrm{i}-(\mathrm{a}-\mathrm{b})}{\mathrm{b}} \text { for }(\mathrm{a}-\mathrm{b})<\mathrm{i}<\mathrm{a} \\
& \mathrm{Bi}=\frac{(\mathrm{a}+\mathrm{c})-\mathrm{i}}{\mathrm{b}} \text { for } \mathrm{a}<\mathrm{i}<(\mathrm{a}+\mathrm{c}) \\
& \qquad \mathrm{Bi}=0 \text { for } \mathrm{i}<(\mathrm{a}-\mathrm{b}) \text { and } \mathrm{i}>(\mathrm{a}+\mathrm{c})
\end{aligned}
$$

The MF ' $\mathrm{B}_{\mathrm{i}}$ ' was estimated at ' $\mathrm{i}$ ' $=0,10,20,30,40,50,60,70,80,90$, and 100 for the overall sensory quality of each sample and quality attributes of chitosancoated fresh cut kiwifruits in general. For each sample on the SFS, the ' $i$ ' value of MF was presented by a set of 10 numbers beginning from $0<\mathrm{i}<10$ to $90<\mathrm{i}<$ 100 , with an interval of 10 , by which the maximum ' $\mathrm{Bi}$ ' values happened in the aforementioned range of 'i'. 
Similarity values estimation and ranking of the chitosan-coated fresh cut kiwifruits

The similarity values of each chitosan-coated fresh cut kiwifruits were calculated using the ' $\mathrm{F}$ ' and 'B' values obtained from each sample and quality attributes on the SFS. The term ' $\mathrm{S}_{\mathrm{m}}$ ' was used to express the similarity values of the sample as $\mathrm{S}_{\mathrm{m}}(\mathrm{F} 1, \mathrm{~B} 1), \mathrm{S}_{\mathrm{m}}(\mathrm{F} 2, \mathrm{~B} 1), \mathrm{S}_{\mathrm{m}}(\mathrm{F} 3, \mathrm{~B} 1), \mathrm{S}_{\mathrm{m}}$ (F4, B1), $\mathrm{S}_{\mathrm{m}}$ (F5, B1) and $\mathrm{S}_{\mathrm{m}}(\mathrm{F} 6, \mathrm{~B} 1)$ while the transpose of matrix $\mathrm{F}$ and $\mathrm{B}$ were expressed by $\mathrm{F}^{\prime}$ and $\mathrm{B}^{\prime}$, respectively and the calculation was done according to the Equation (5). The rule of matrix multiplication was followed for the analysis of similarity values of both samples and quality attributes (Routray and Mishra, 2012). After calculation, the similarity values were then compared among each other for maximum values to get a better ranking. The ranking decreases with the decreasing value of similarity values.

$$
\mathrm{S}_{\mathrm{m}}(\mathrm{F}, \mathrm{B})=\frac{\mathrm{F} \times \mathrm{B}^{\prime}}{\max \left(\mathrm{F} \times \mathrm{F}^{\prime} \text { and } \mathrm{B} \times \mathrm{B}^{\prime}\right)}
$$

(5)

\section{RESULTS AND DISCUSSION}

\section{Outcome of the fuzzy assisted modeling}

The sensory evaluation of chitosan-coated fresh cut kiwi fruits is an uncertain phenomenon that leads to an incorrect human interpretation. The vagueness and uncertainty in the sensory data could be minimized mathematically using fuzzy set theory. This theory converts the degree of vagueness in human analytical to number system by considering the linguistic scores given by the judges and then converting them into numerical values. The chitosan-coated fresh cut kiwi fruit samples to be evaluated would be given to each judge, along with the fuzzy logic score sheet. All the judges mark their preference in linguistic terms, i.e., not satisfactory, fair, medium, good, and excellent. The score sheets were collected and checked for how many numbers of judges who gave their preference for not satisfactory for a specific sample and quality attribute. Similarly, the same process followed for fair, medium, good, and excellent, as shown in Table 1 and 2

Table 1 Sum of sensory scores for quality attributes of kiwi samples

\begin{tabular}{lccccc}
\hline \multirow{2}{*}{$\begin{array}{l}\text { Quality } \\
\text { attributes }\end{array}$} & \multicolumn{2}{c}{ Sensory scale factors } & & & \\
\cline { 2 - 4 } & $\begin{array}{c}\text { Not } \\
\text { Satisfactory }\end{array}$ & Fair & Medium & Good & Excellent \\
\hline Color & 0 & 1 & 1 & 4 & 9 \\
S1 & 0 & 1 & 3 & 5 & 6 \\
S2 & 2 & 2 & 6 & 1 & 4 \\
S3 & 10 & 4 & 1 & 1 & 0 \\
S4 & & & & & \\
Smell & 0 & 0 & 2 & 8 & 5 \\
S1 & 1 & 1 & 5 & 6 & 2 \\
S2 & 0 & 2 & 8 & 5 & 0 \\
S3 & 12 & 2 & 2 & 0 & 0 \\
S4 & & & & & \\
Taste & 0 & 1 & 1 & 5 & 8 \\
S1 & 0 & 1 & 2 & 2 & 10 \\
S2 & 2 & 6 & 2 & 3 & 2 \\
S3 & 14 & 2 & 0 & 0 & 0 \\
S4 & & & & & \\
Texture & & & & & \\
S1 & 0 & 0 & 2 & 6 & 7 \\
S2 & 1 & 0 & 5 & 7 & 2 \\
S3 & 3 & 2 & 5 & 4 & 1 \\
S4 & 11 & 3 & 1 & 0 & 0 \\
\hline & & & & & \\
\hline
\end{tabular}

Table 2 Sum of individual preferences to the importance of quality attributes of chitosan coated samples

\begin{tabular}{lccccc}
\multicolumn{2}{l}{$\begin{array}{l}\text { Quality attributes } \\
\text { factors }\end{array}$} & \multicolumn{1}{l}{ Sensory scale } \\
\hline & $\begin{array}{c}\text { Not } \\
\text { important }\end{array}$ & $\begin{array}{c}\text { Somewhat } \\
\text { important }\end{array}$ & Important & $\begin{array}{c}\text { Highly } \\
\text { important }\end{array}$ & $\begin{array}{c}\text { Extremely } \\
\text { important }\end{array}$ \\
Color & 1 & 1 & 2 & 7 & 4 \\
Smell & 0 & 0 & 1 & 4 & 10 \\
Taste & 0 & 0 & 3 & 4 & 8 \\
Texture & 1 & 2 & 2 & 5 & 5 \\
\hline
\end{tabular}

Triplets for sensory scores of chitosan-coated freshcut kiwifruits and judges' rating on the quality attributes

Among the quality attributes, the maximum preference was given for extremely important in smell (10) and taste (8). While in color, the maximum preference was given for the highly important. According to the judges, smell and taste could be the most influencing quality attributes in the case of the chitosan-coated fresh cut kiwifruits. The triplets for the sensory score were calculated using sensory score choices given for each chitosan-coated samples, and the triplets related to the sensory scores (Jha et al., 2015). Likewise, the triplets for sensory scores of the quality attributes were determined using sensory score preferences given for the quality attributes and triplets related to the sensory scores. The triplets for sensory scores of all the samples and quality attributes are given in Table 3. The maximum number of judges (more than 10) gave preference for highly important and extremely important categories in all the quality attributes. Equal preference (5) was given for texture attributes, and the highest preference in the highly important category for color quality attributes for chitosan-coated fresh cut kiwi fruits.

Table 3 Triplets associated with the sensory scores for the quality attributes

Triplets for sensory scores
Color
$\mathrm{S} 1 \mathrm{C}=(85.00,25.00,10.00)$
$\mathrm{S} 2 \mathrm{C}=(76.67,25.00,15.00)$
$\mathrm{S} 3 \mathrm{C}=(55.00,21.67,18.33)$
$\mathrm{S} 4 \mathrm{C}=(14.06,9.38,25.00)$
Smell
$\mathrm{S} 1 \mathrm{~S}=(80.00,25.00,16.67)$
$\mathrm{S} 2 \mathrm{~S}=(61.67,23.33,21.67)$
$\mathrm{S} 3 \mathrm{~S}=(55.00,25.00,25.00)$
$\mathrm{S} 4 \mathrm{~S}=(9.38,6.25,25.00)$
Taste
$\mathrm{S} 1 \mathrm{~T}=(83.33,25.00,11.67)$
$\mathrm{S} 2 \mathrm{~T}=(85.00,25.00,8.33)$
$\mathrm{S} 3 \mathrm{~T}=(45.00,21.67,21.67)$
$\mathrm{S} 4 \mathrm{~T}=(3.13,3.13,25.00)$
Texture
$\mathrm{S} 1 \mathrm{Tx}=(83.33,25.00,13.33)$
$\mathrm{S} 1 \mathrm{Tx}=(65.00,23.33,21.67)$
$\mathrm{S} 1 \mathrm{Tx}=(46.67,20.00,23.33)$
$\mathrm{S} 1 \mathrm{Tx}=(8.33,6.67,25.00)$

Triplets and relative weighting for sensory scores of quality attributes

The triplets for OSSs of chitosan-coated fresh cut kiwi fruits were calculated using triplets for sensory scales of the samples and the relative weightages of their quality attributes. The relative weightage for triplets of each quality attribute was calculated using $\mathrm{Q}_{\text {sum, }}$ i.e., the sum of the first term of the triplets for sensory score $(70.00,90.00,83.33,68.33)$, as shown in Table 4 . While the triplets for sensory scores of the quality attributes were determined using the triplets related to the sensory scores and preferences provided by the judges for all the attributes (Table 5). For example, in the first quality attribute (color), the preferences given by the judges were: not at all important (1), somewhat important (1), important (2), highly important (7), and extremely important (4). The first term of the triplets of quality attributes corresponding to the linguistic terms was found to be $56.73,24.04$, and 23.07, as calculated by Equation (1). While the triplets for the OSSs of the sample S1 (SO1) were presented in Equation (6) that was determined using Equation (2) mentioned earlier.

Table 4 Triplets associated with sensory scores of quality attributes and the relative weightage for quality attribute of chitosan coated samples

\begin{tabular}{|c|c|c|}
\hline $\begin{array}{l}\text { Quality } \\
\text { attributes }\end{array}$ & $\begin{array}{c}\text { Triplets for sensory } \\
\text { scores }\end{array}$ & $\begin{array}{c}\text { Triplets for relative } \\
\text { weightage }\end{array}$ \\
\hline Color & $\mathrm{QC}=\left(\begin{array}{l}70.0023 .3318 .33\end{array}\right)$ & QCrel $=\left(\begin{array}{lll}0.23 & 0.08 & 0.06\end{array}\right)$ \\
\hline Smell & $\mathrm{QS}=\left(\begin{array}{lll}90.00 & 25.00 & 8.33\end{array}\right)$ & QSrel $=\left(\begin{array}{lll}0.29 & 0.08 & 0.03\end{array}\right)$ \\
\hline Taste & $\mathrm{QT}=\left(\begin{array}{l}83.3325 .0011 .67\end{array}\right)$ & QTrel $=\left(\begin{array}{lll}0.27 & 0.08 & 0.04\end{array}\right)$ \\
\hline Texture & QTx $=\left(\begin{array}{llll}68.33 & 25.00 & 16.67\end{array}\right)$ & QTxrel $=\left(\begin{array}{lll}0.22 & 0.08 & 0.05\end{array}\right)$ \\
\hline
\end{tabular}

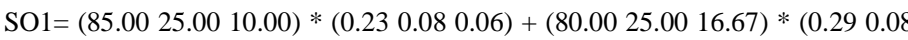
$0.03)+(83.3325 .0011 .67) *(0.270 .080 .04)+(83.3325 .0013 .33) *(0.220 .08$ $0.05)$

Similarly, for the samples S2 (SO2), S3 (SO3), and S4 (SO4), the triplets for OSSs were calculated and shown as follow:

$\mathrm{SO} 1=82.7551 .1527 .82$

$\mathrm{SO} 2=72.0146 .8729 .42$

$\mathrm{SO} 3=50.5038 .1531 .13$

SO4 = 8.53 8.9326.64 
Overall membership functions (OMFs) of sensory scores on the standard fuzzy scale (SFS)

The values of OMFs of the chitosan-coated fresh cut kiwifruit samples and the quality attributes were calculated using the triplets for OSSs of the samples and quality attributes (Table 5). The triplets $(a, b, c)$ for all the samples, and the attributes were used for calculation at 0 to 100 following Equation (4). For example, in $1 \%$ chitosan-coated fresh cut kiwifruits, the triplets (82.75 51.15 27.82) were used to calculate 'B' value at every level from 0 to 90 (Jha $\boldsymbol{e t}$ al., 2015). The values of OMFs for all the samples and quality attributes were presented in Table 7.

Table 5 Overall Membership function of sensory scores on standard fuzzy scale
\begin{tabular}{llccccccccc} 
b1 & 0 & 0 & 0 & 0.164 & 0.360 & 0.555 & 0.751 & 0.946 & 1 & 0.739 \\
b2 & 0 & 0 & 0.104 & 0.317 & 0.531 & 0.744 & 0.957 & 1 & 0.728 & 0.388 \\
b3 & 0 & 0.200 & 0.463 & 0.725 & 0.987 & 1 & 0.695 & 0.374 & 0.052 \\
b4 & 1 & 0.945 & 0.569 & 0.194 & 0 & 0 & 0 & 0 & 0 \\
\hline
\end{tabular}

\section{Similarity values of chitosan-coated fresh cut kiwi fruits and the quality} attributes and their ranking

The similarity values ( 0 to 1$)$ help in finding the best sample and quality attribute based on the ranking. The highest similarity value among all the four samples was in a good category, which gets the top priority and is chosen as the best sample. If two samples fall into the same category, then the highest similarity score will be given preference and declared as the best sample. Similarly, the same approach was followed for other samples and quality attributes and presented in Tables 6 and 7, respectively. The calculation of the similarity values depends on the membership functions and F values (F1 to F6) (Jha et al., 2015) In chitosan-coated fresh cut kiwi fruit samples, sample 1 falls in the good category, sample 2 falls in medium, sample 3 falls in satisfactory, and sample 4 falls under fair category with high similarity scores of $0.78,0.70,0.72$, and 0.94 , respectively. Sample 1 with 0.78 was given preference according to the similarity ranking rules (Jha et al., 2015). Therefore, the order of preference among chitosan-coated fresh cut kiwi fruit samples were shown as S1 (good) > S2 (medium) $>\mathrm{S} 3$ (satisfactory) $>\mathrm{S} 4$ (fair). The treatment of chitosan showed a significant difference in consumer preference. Higher the concentration of the chitosan higher the consumer preference with high similarity values. The result for similarity values of quality attributes confirmed that, for chitosan-coated fresh cut kiwifruits, color $($ good $)=$ smell $($ good $)=$ taste $($ good $)>$ texture $($ medium $)$ The results revealed that the color, smell, and taste are the important quality attribute in the case of chitosan-coated fresh cut kiwi fruits, followed by texture (Table 7)

Table 6 Similarity values for chitosan coated samples

\begin{tabular}{lcccc}
\hline Scale factor & S1 & S2 & S3 & S4 \\
\hline Not satisfactory & 0 & 0 & 0.03 & 0.65 \\
Fair & 0.02 & 0.07 & 0.30 & 0.94 \\
Satisfactory & 0.23 & 0.36 & 0.72 & 0.21 \\
Medium & 0.57 & 0.70 & 0.70 & 0 \\
Good & 0.78 & 0.68 & 0.23 & 0 \\
Excellent & 0.36 & 0.21 & 0.01 & 0 \\
\hline
\end{tabular}

Table 7 Similarity values of quality attributes of the fresh cut kiwifruits

\begin{tabular}{lcccc} 
Scale factor & S1 & S2 & S3 & S4 \\
\hline Not necessary & 0 & 0 & 0 & 0 \\
Somewhat necessary & 0 & 0 & 0 & 0 \\
Important & 0.05 & 0 & 0.02 & 0.25 \\
Medium & 0.78 & 0.21 & 0.45 & 0.93 \\
Good & 0.99 & 0.92 & 0.97 & 0.70 \\
Extremely important & 0.15 & 0.63 & 0.43 & 0.06
\end{tabular}

\section{CONCLUSION}

Different concentrations of chitosan-coated fresh cut kiwifruits samples were placed for sensory evaluation by a panel of 15 judges using fuzzy logic modeling. It was observed that the $1 \%$ chitosan-coated samples ranked first, followed by $0.8 \%, 0.6 \%$ and $0 \%$ samples on second, third and fourth respectively i.e. S1 (good) $>$ S2 (medium) $>$ S3 (satisfactory) $>$ S4 (fair). Important quality attributes of chitosan-coated samples were rated as: color $=$ smell $=$ taste $>$ texture (medium). Therefore, results revealed that the color, smell, and taste were the important quality attributes of fresh cut kiwifruit for determining the acceptability of the fresh cut fruits in the market.

\section{REFERENCES}

Amodio, M. L., Colelli, G., Hasey, J. K., \& Kader, A. A. (2007). A comparative study of composition and postharvest performance of organically and conventionally grown kiwifruits. Journal of the Science of Food and Agriculture, 87(7), 1228-1236. https://doi.org/10.1002/jsfa.2820
Das, H. (2005). Food processing operations analysis. Global Media https://books.google.co.in/books/about/Food_Processing_Operations_Analysis.ht ml?id=b4GfGdRQ93QC

Fattahi, J., Fifall, R., \& Babri, M. (2010). Postharvest quality of kiwifruit (Actinidia deliciosa cv. Hayward) affected by pre-storage application of salicylic acid. South Western Journal of Horticulture Biology and Environment, 1(2), 175 186. http://biozoojournals.ro/swihbe/v1n2/08.swjhbe.v1n2.Fattahi.pdf

Helander, I. M., Nurmiaho-Lassila, E. L., Ahvenainen, R., Rhoades, J., \& Roller, S. (2001). Chitosan disrupts the barrier properties of the outer membrane of Gram-negative bacteria. International Journal of Food Microbiology, 71(2-3), 235-244. https://doi.org/ 10.1016/s0168-1605(01)00609-2

Hernandez-Munoz, P., Almenar, E., Del Valle, V., Velez, D., \& Gavara, R. (2008). Effect of chitosan coating combined with postharvest calcium treatment on strawberry (Fragaria $\times$ ananassa) quality during refrigerated storage. Food Chemistry, 110(2), 428-435. https://doi.org/10.1016/j.foodchem.2008.02.020

Jaya, S., \& Das, H. (2003). Sensory evaluation of mango drinks using fuzzy logic. Journal of sensory studies, 18(2), 163-176. https://doi.org/10.1111/j.1745 459X.2003.tb00382.X

Jha, P., Das, A. J., Dash, K. K., \& Deka, S. C. (2015). Sensory evaluation of black pigmented rice (Oryza sativa cv. Poireton) wine fortified with probiotic Lactobacillus acidophilus ATCC 4356 and Lactobacillus sakei ATCC 15521 using fuzzy logic. Journal of the Institute of Brewing, 121(4), 566-573. https://doi.org/10.1002/jib.247

Knorr, D., Zenker, M., Heinz, V., \& Lee, D. U. (2004). Applications and potential of ultrasonics in food processing. Trends in Food Science \& Technology, 15(5), 261-266. https://doi.org/10.1016/j.tifs.2003.12.001

Lazim, M. A., \& Suriani, M. (2009). Sensory evaluation of the selected coffee products using fuzzy approach. World Academy of Science, Engineering and Technoly International Journal of Mathematical and Computational Sciences, 50(2) https://citeseerx.ist.psu.edu/viewdoc/download?doi=10.1.1.193.2113\&rep=rep $1 \&$ type $=$ pdf

Lin, L., Wang, B., Wang, M., Cao, J., Zhang, J., Wu, Y., \& Jiang, W. (2008) Effects of a chitosan-based coating with ascorbic acid on post-harvest quality and core browning of 'Yali'pears (Pyrus bertschneideri Rehd.). Journal of the Science of Food and Agriculture, 88(5), 877-884. https://doi.org/10.1002/jsfa.3164

Martinez, L. (2007). Sensory evaluation based on linguistic decision analysis International Journal of Approximate Reasoning, 44(2), 148-164. https://doi.org/10.1016/j.ijar.2006.07.006

Meng, X., Li, B., Liu, J., \& Tian, S. (2008). Physiological responses and quality attributes of table grapefruit to chitosan preharvest spray and postharvest coating during storage. Food Chemistry, 106(2), 501-508. https://doi.org/10.1016/j.foodchem.2007.06.012

Pen, L. T., \& Jiang, Y. M. (2003). Effects of chitosan coating on shelf life and quality of fresh cut Chinese water chestnut. LWT-Food Science and Technology, 36(3), 359-364. https://doi.org/10.1016/S0023-6438(03)00024-0

Perrot, N., Ioannou, I., Allais, I., Curt, C., Hossenlopp, J., \& Trystram, G. (2006) Fuzzy concepts applied to food product quality control: A review. Fuzzy sets and systems, 157(9), 1145-1154. https://doi.org/10.1016/i.fss.2005.12.013

Routray, W., \& Mishra, H. N. (2012). Sensory evaluation of different drinks formulated from dahi (indian yogurt) powder using fuzzy logic. Journal of Food Processing and Preservation, 36(1), 1-10. https://doi.org/10.1111/j.17454549.2011.00545.x

Sinija, V. R., \& Mishra, H. N. (2011). Fuzzy analysis of sensory data for quality evaluation and ranking of instant green tea powder and granules. Food and Bioprocess Technology, 4(3), 408-416. https://doi.org//10.1007/s11947-0080163-x?shared-article-renderer

Stojanovic, J., \& Silva, J. L. (2007). Influence of osmotic concentration, continuous high frequency ultrasound and dehydration on antioxidants, color and chemical properties of rabbiteye blueberries. Food chemistry, 101(3), 898-906 https://doi.org/10.1016/j.foodchem.2006.02.044

Vivek, K., Subbarao, K. V., \& Srivastava, B. (2016). Optimization of postharvest ultrasonic treatment of kiwifruit using RSM. Ultrasonics sonochemistry, 32, 328335. https://doi.org/10.1016/j.ultsonch.2016.03.029

Vivek, K., KV, S. R., Singh, S. S., \& Mishra, S. (2019). Engineering Properties and Shelf Life of Freshly Harvested Indian Kiwi Cultivars for Facilitating 
Primary Processing. Carpathian Journal of Food Science \& Technology, 11(3),

107-120. https://doi.org/10.34302/crpjfst/2019.11.3.10

Zhang, D., \& Quantick, P. C. (1997). Effects of chitosan coating on enzymatic browning and decay during postharvest storage of litchi (Litchi chinensis Sonn.)

fruit. Postharvest Biology and Technology, 12(2), 195-202.

https://doi.org/10.1016/S0925-5214(97)00057-4 